\title{
Changes in the oral flora in Sjögren's syndrome
}

\author{
T. W. MacFARLANE AND D. K. MASON \\ From the Department of Oral Medicine and Pathology, Glasgow Dental Hospital and School, Glasgow
}

SYNOPSIS The oral flora of 10 patients with Sjögren's syndrome was compared with that of 10 health control subjects. Significantly greater numbers of Candida albicans, Staphylococcus aureus, an@्尺. coliform bacilli were present in the Sjögren's group. Possible reasons for these changes are disల̊ cussed.

In Sjögren's syndrome, which is characterized by chronic inflammation of the lacrimal and salivary glands (Sjögren, 1933), there is commonly dryness of the lips and the oral mucosa with the secretion of thick, ropy saliva. The symptoms may be sufficiently severe to interfere with mastication and produce angular cheilitis and atrophy of the oral mucosa. An increase in the incidence of dental caries following the development of xerostomia due to Sjögren's syndrome has been reported by Bloch, Buchanan, Wahl, and Bunim (1965).

It is generally accepted that the composition of the commensal oral flora is controlled by complex interactions among the oral microorganisms themselves (Björnesjö, 1950), the host tissues, and the mechanical washing action and antimicrobial activity of saliva (Bibby, Hine, and Clough, 1938; Van Kesteren, Bibby, and Berry, 1942; Kerr and Wedderburn, 1958; MacFarlane and Mason, 1972). If one of these factors is greatly altered, for example, virtual cessation of salivary secretion, changes might be expected to occur in the oral flora. This study was carried out to discover whether a difference existed in the oral flora of patients with xerostomia due to Sjögren's syndrome compared with normal healthy controls.

\section{Patients and Methods}

The study comprised 20 patients, 10 diagnosed cases of Sjögren's syndrome and 10 healthy controls. The test and control groups were matched for age, sex, denture, and dental status; the results are shown in table II. The diagnosis of Sjögren's syndrome was based on the criteria described by Bloch et al (1965). Both patients and controls were questioned regarding a history of xerostomia and of the associated symp-

Received for publication 5 March 1974. toms of Sjögren's syndrome. None of the contro $\Phi$ patients had symptomatic or clinical dry mouth and parotid salivary flow studies were carried out only on the 10 patients with Sjögren's syndrome. The flow studies were performed by the use of a modified Carlson-Crittenden cup, with an outer chamber of diameter $20 \mathrm{~mm}$ and an inner chamber of diametei $10 \mathrm{~mm}$ (Carlson and Crittenden, 1910; Masono Harden, and 'Alexander, (1966). Parotid saliva was collected from each patient after stimulation with $10 \%$ citric acid. The flow rate results were assesse as normal or abnormal after comparing with the normal range as defined by Chisholm (1970) an $\vec{B}$ Whaley, Williamson, Chisholm, Webb, Mason, and Buchanan (1973). None of the patients or controlst gave a recent history of taking antimicrobial agents:The criteria for a diagnosis of candidosis were clinicap evidence of oral inflammation, together with smears from the inflamed area showing yeasts in the hyphaß form, and a swab yielding a moderate or heavis growth of a candida species.

\section{Microbiology}

Four separate areas of the mouth were sampled for the microbiological investigation; the fitting surface of the upper denture or palate, the dorsum of the tongue, the right tonsillar area, and the buccat mucosa in the region of the right parotid duct orio fice. Each area was sampled by means of a firmly take cotton wool swab. The swab was immediately im mersed in $1 \mathrm{ml}$ of sterile deionized water, thoroughlys agitated, and squeezed to transfer the sampled material to the fluid. All the swabs were taken by ones. operator and before salivary flow studies were्ठ carried out. Within 15 minutes of the time of sampling $0.05 \mathrm{ml}$ of each sample was inoculateof evenly onto the following culture plates: blood agar Sabouraud's, MacConkey's, and salt agar plate. AlB 
cultures were incubated aerobically at $37^{\circ} \mathrm{C}$ for two days. The plates were examined and the numbers of yeasts (Sabouraud's agar), staphylococci (salt agar), and coliforms (MacConkey's agar) noted. Sample colonies from each of the plates were removed, and identified by the following criteria: yeasts by means of germ tube production and sugar fermentation reactions; Staphylococcus aureus by coagulase production; and coliform organisms by the techniques used by Cowan and Steel (1965). The numbers of colonies of each organism isolated from the four areas of the mouth were graded as shown in table I. By adding the grading values for each of the areas of the oral cavity a mouth score (0-12) for each organism was obtained.

\begin{tabular}{ll}
\hline Grade & Number of Colonies \\
\cline { 2 - 2 } 0 & Absent \\
1 & $1-10$ \\
2 & $11-40$ \\
3 & Over 40 \\
\hline
\end{tabular}

Table I Grading standards for number of colonies isolated

\section{Results}

Table II shows a comparison of the clinical data of the two groups. None of the Sjögren's group had clinical evidence of oral candidosis at the time of sampling.

The salivary flow rates and individual and total mouth scores for yeasts, Staphylococcus aureus, and coliform bacilli in the Sjögren's group are shown in table III. In seven patients no measurable parotid secretion was obtained; three patients had reduced secretion and none of the patients had a flow rate which was within normal limits. All 10 patients had Candida albicans in the mouth; eight also had Staphylococcus aureus present and three patients had, in addition, various coliform bacilli. The total mouth score for the 10 Sjögren patients was Candida albicans 80, Staphylococcus aureus 74, and coliform bacilli 21. Although patients with no measurable parotid secretion tended to have a higher mouth score than those with reduced flow rate there were exceptions, eg, patient A8 with no measurable parotid flow but a mouth score of 3 .

The individual and total mouth scores for yeasts, Staphylococcus aureus, and coliform bacilli in the control group of patients are shown in table IV. Four patients had yeasts present in the mouth, and one of these had, in addition, a few colonies of

\begin{tabular}{llll}
\hline Patient & Yeasts & $\begin{array}{l}\text { Stapylococcus } \\
\text { aureus }\end{array}$ & $\begin{array}{l}\text { Coliform } \\
\text { Bacilli }\end{array}$ \\
\hline C1 & 0 & 0 & 0 \\
C2 & 2 & 0 & 0 \\
C3 & 0 & 0 & 0 \\
C4 & 0 & 0 & 0 \\
C5 & 1 & 1 & 0 \\
C6 & 3 & 0 & 0 \\
C7 & 0 & 5 & 0 \\
C8 & 4 & 0 & 0 \\
C9 & 0 & 3 & 0 \\
C10 & 0 & 0 & 0 \\
Total score & 10 & 9 & 0 \\
\hline
\end{tabular}

Table IV Mouth scores for 10 control patients

\begin{tabular}{lllllll}
\hline Clinical Diagnosis & No. of Patients & \multicolumn{2}{l}{ Sex } & & Mean Age (yr) & No. with Denture \\
\cline { 2 - 5 } & & Male & Female & & \\
\hline Sjögren's syndrome & 10 & 1 & 9 & 56 & 8 & 9 \\
Control patients & 10 & 1 & 9 & 58 & 1 \\
\hline
\end{tabular}

Table II Age and sex distribution of patients

\begin{tabular}{|c|c|c|c|c|}
\hline Patient & Salivary Flow ${ }^{1}$ & Yeasts & Staphylococcus aureus & Coliform Bacilli \\
\hline $\begin{array}{l}\text { A1 } \\
\text { A2 } \\
\text { A3 } \\
\text { A4 } \\
\text { A5 } \\
\text { A6 } \\
\text { A7 } \\
\text { A8 } \\
\text { A9 } \\
\text { A10 }\end{array}$ & $\begin{array}{l}x \\
x \\
x \\
x \\
x \\
= \\
\frac{x}{x}\end{array}$ & $\begin{array}{r}10 \\
12 \\
9 \\
11 \\
7 \\
4 \\
8 \\
3 \\
5 \\
11\end{array}$ & $\begin{array}{r}8 \\
11 \\
10 \\
11 \\
3 \\
9 \\
10 \\
0 \\
0 \\
12\end{array}$ & $\begin{array}{r}0 \\
11 \\
4 \\
0 \\
0 \\
0 \\
6 \\
0 \\
0 \\
0\end{array}$ \\
\hline Total score & & 80 & 74 & 21 \\
\hline
\end{tabular}

Table III Mouth scores for 10 patients with Sjögren's syndrome

1 - Reduced secretion, $\times$ no measurable flow 
Staphylococcus aureus. Two patients had Staphylococcus aureus alone present. None of the control patients had any coliform bacilli present. The total mouth scores for the 10 control patients was Candida albicans 10, Staphylococcus aureus 9, and coliform bacilli 0 . The difference in the numbers of yeasts and Staphylococcus aureus between the two groups was significant at the 0.001 level using the Mann Whitney $U$ test. The yeasts isolated from both the Sjögren's and the control groups were identified as Candida albicans. Two of the coliform bacilli were identified as Escherichia coli and one as Enterobacter liquifaciens.

\section{Discussion}

The results of this preliminary study show that with regard to yeasts, Staphylococcus aureus, and perhaps coliform bacilli, there are distinct differences in the oral flora of patients with Sjögren's syndrome compared with that of normal healthy controls.

The precise reason for the increase in the incidence and number of these microorganisms is not clear.

Some strains of Escherichia coli are inhibited by the salivary thiocyanate peroxidase antilactobacillus system (Klebanoff, Clem, and Luebke, 1966). Many strains of Staphylococcus aureus are inhibited by saliva (Bibby et al, 1938) but the nature of the inhibitory factor is not known. In contrast to $E$. coli and Staphylococcus aureus, saliva from normal healthy adults appears to have no inhibitory effect on yeasts. Lehner (1965) has shown that patients with candidosis secrete antibodies against the yeast in their saliva. The loss of these inhibitory factors, together with the malfunction of the mechanical washing action of saliva, may partially explain our findings. Llory, Dammron, and Frank (1971) reported changes in the salivary and dental plaque microbial flora of patients whose salivary glands had been irradiated in the treatment of cervico-facial carcinoma. The numbers of cariogenic lactic bacteria (streptococci and lactobacilli) were increased but no quantitative increase in Staphylococcus aureus or coliform bacilli was noted. Yeasts were not mentioned at any stage of their investigations, which contrast with the present study where all the patients with xerostomia had yeasts present in the oral flora.

In relation to the number of yeasts present in the Sjögren's group, it is interesting to note that Young, Resca, and Sullivan (1951), investigating the number of yeasts in the mouths of healthy young adults, found that the numbers of yeasts isolated varied inversely with salivary $\mathrm{pH}$. For example, the few subjects with a salivary pH of 5 to 5.5 had a $91 \%$ carrier rate for yeasts compared with a $52 \%$ carrier rate at salivary $\mathrm{pH} 6.5$. It is known that patients with xerostomia due to irradiation for carcinoma have low salivary pH values (Frank, Herdly, and Philippe, 1965). Similar pH values for patients with severe Sjögren's syndrome are not available. How-o ever, preliminary studies carried out on four patients $\overline{-}$ suggest that the salivary $\mathrm{pH}$ of patients with $\overline{\overline{\bar{\omega}}}$ Sjögren's syndrome, all of whom had very low flow rates, was $4 \cdot 5-5 \cdot 5$. These findings are not surprisingo since salivary $\mathrm{pH}$ varies directly with flow rate (Jenkins 1960). If these findings are substantiated. low salivary $\mathrm{pH}$ may explain the increase in the $\overrightarrow{\vec{H}}$ number of yeasts in patients with Sjögren's syndrome, $\omega$ although the low pH may be due to the large numbero of yeasts present in the mouth.

None of the Sjögren's group had active yeast. infections at the time of the microbiological inves- $\rightarrow$ tigation. However, an examination of the casea histories of the Sjögren's group, both before ando after the microbiological tests, revealed that five hadcandidosis on one occasion and two patients hadz candidosis on more than one occasion.

The clinical implication of these findings is that $\vec{\bullet}$ we should not accept the inflamed dry mucosa some- $\rightarrow$ times seen in Sjögren's syndrome as inevitable due to decreased salivary flow rate; from our results it is just as likely that the inflammation is due to, or associated with, active Candida infection. Thus patients with xerostomia due to Sjögren's syndrome $\frac{0}{\varnothing}$ should be kept under regular clinical and micro- $\stackrel{\varrho}{\rightarrow}$ biological surveillance for recurrence of candidosis.

\section{References}

Bibby, B. G., Hine, M. K., and Clough, O. W. (1938). The antibacterial action of human saliva. J. Amer. dent. Ass., 25, 1290-1302.

Björnesjö, K. B. (1950). Studies on the antibacterial factors of human. saliva. Acta chem. scand., 4, 835-845.

Bloch, K. J., Buchanan, W. W., Wohl, M. J., and Bunim, J. J. (1965). Sjögren's syndrome: a clinical pathological and serological study of 62 cases. Medicine (Baltimore), 44, 187-231.

Carlson, A. J., and Crittenden, A. L. (1910). The relation of ptyalin concentration to the diet, and to the rate of secretion of $D$ the saliva. Amer. J. Physiol., 26, 169.

Chisholm, D. M. (1970). The salivary glands and their secretions in connective tissue disease. PhD Thesis, Glasgow University. N

Cowan, S. T., and Steel, K. J. (1965). Manual for the Identification of: Medical Bacteria, 1st ed., pp. 76-82. University Press, Cam-N bridge.

Frank, R. M., Herdly, J., and Philippe, E. (1965). Acquired dental defects and salivary gland lesions after irradiation for carcinoma. J. Amer. dent. Ass., 70, 868-883.

Jenkins, G. N. (1960). The Physiology of the Mouth, 3rd ed., pp. 302 304. Blackwell, Oxford.

Kerr, A. C., and Wedderburn, D. L. (1958). Antibacterial factors in the secretions of human parotid and submaxillary glands.? Brit. dent. J., 105, 321-326.

Klebanoff, S. J., Clem, W. H., and Luebke, R. G. (1966). The peroxidase-thiocyanate-hydrogen peroxide antimicrobial system. Biochim. biophys. Acta (Amst.), 117, 63-72.

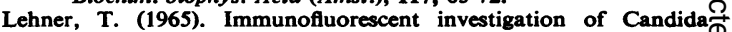
albicans antibodies in human saliva. Arch. oral Biol., 10, 975-980.

Llory, H., Dammron, A., and Frank, R. M. (1971). Les modifications de la flore buccale aerobie apres radiotherapie buccopharyngee. Arch. oral Biol., 16, 617-630. 
MacFarlane, T. W., and Mason, D. K. (1972). Local environmental factors in the host resistance to the commensal microflora of the mouth. In Host Resistance to Commensal Bacteria, edited by T. MacPhee, pp. 64-75. Churchill Livingstone, Edinburgh and London.

Mason, D. K., Harden, R. M., and Alexander, W. D. (1966). The influence of flow rate on the salivary iodide concentration in man. Arch. oral Biol., 11, 235-246.

Sjögren, H. (1933). Zur Kenntnis der Keratoconjunctivitis sicca.
Acta ophthal. (Kbh.), Suppl. 2.

Van Kesteren, M., Bibby, B. G., and Berry, G. P. (1942). Studies on the antibacterial factors of human saliva. J. Bact., 43, 573-582.

Whaley, K., Williamson, J., Chisholm, D. M., Webb, J., Mason, D. K., and Buchanan, W. W. (1973). Sjøgren's syndrome. Ouart. J. Med., 42, 279-304.

Young, G., Resca, H. G., and Sullivan, M. T. (1951). The yeasts of the normal mouth and their relation to salivary acidity. J. dent. Res., 30, 426-430. 